\title{
Polysaccharide-Polynucleotide Complexes Part 17. Solvent Effects on Conformational-Transition of Polydeoxyadenylic Acid in the Complexes with Schizophyllan
}

\author{
Masami Mizu, Kazuya Koumoto, Taro Kimura, ${ }^{*}$ \\ Kazuo SAKURAI, ${ }^{\dagger}$ and Seiji SHINKAI** \\ Department of Chemical Process \& Environments, The University of Kitakyushu, 1-1 Hibikino, \\ Wakamatu-ku, Kitakyushu, Fukuoka 808-0135, Japan \\ *Biotechnology and Food Research Institute, Fukuoka Industrial Technology Center, 1465-5 Aikawa, \\ Kurume, Fukuoka 839-0861, Japan \\ ${ }^{* *}$ Faculty of Engineering Department of Chemistry \& Biochemistry, Graduate School of Engineering, \\ Kyushu University, 6-10-1 Hakozaki, Higashi-ku, Fukuoka, Fukuoka 812-8581, Japan
}

(Received May 9, 2003; Accepted July 7, 2003)

\begin{abstract}
This paper examines the relationship between the conformation and solvent for the poly(dA)/s-SPG complex using circular dichroism in the $240-300 \mathrm{~nm}$ wavelength region. At the low temperature and low salt concentration, poly $(\mathrm{dA})$ in the complex is estimated to take $C 2^{\prime}$-endo with a different torsional angle from the anti form. With increasing temperature, the circular dichroism (CD) spectrum starts to bear characteristics of $C 3^{\prime}$-endo and anti as a minority among the majority of $C 2^{\prime}$-endo and anti. When the salt concentration is increased, the spectrum becomes almost identical to that of the high temperature form under the non-salt condition. Therefore, addition of salt provides the identical effect to increasing temperature. $\mathrm{D}_{2} \mathrm{O}$ induces the same effect as decreasing temperature.
\end{abstract}

KEY WORDS Polysaccharide-Polynucleotide Complex / Thermodynamics / Solvent Effect /

$\beta$-1,3-Glucan / Circular Dichroism / Polynucleotide /

Conformational changes in polynucleotides play important roles in biological systems. ${ }^{1}$ A replication fork in DNA undergoes a conformational change when it interacts with a single-stranded polynucleotide binding protein $(\mathrm{SSB}){ }^{2}$ This change disables the replication fork to retrieve hybridization, which is crucial to DNA replication. Powell and Gray ${ }^{3}$ explored the conformational change induced by SSB, using poly(dA) as a model single-stranded DNA (ssDNA). Their circular dichroism (CD) data demonstrated that SSB induces the same conformational change in poly $(\mathrm{dA})$ as that of heating poly $(\mathrm{dA})$ or protonating the polymer at low $\mathrm{pH}$. It seems that ssDNAs conformational response to external stimuli is one of the crucial issues to understand the relationship between ssDNA conformation and biological roles. ${ }^{1,2}$

Sakurai and Shinkai ${ }^{4}$ are the first to demonstrate that a neutral $\beta$-1,3-glucan schizophyllan (SPG) can bind single homo-polynucleotides to change the conformation dramatically. Here, SPG is produced by Schizophyllun commune and belongs to the $\beta$-1,3-glucan family (Figure 1). ${ }^{5}$ SPG exists in a triple helix in water and a single chain (s-SPG) in dimethyl sulfoxide (DMSO). ${ }^{6,7}$ When a s-SPG/DMSO solution is diluted with water (renature), SPG can gain the triple helical conformation again. ${ }^{8}$ When some polynucleotide

${ }^{\dagger}$ To whom correspondence should be addressed.

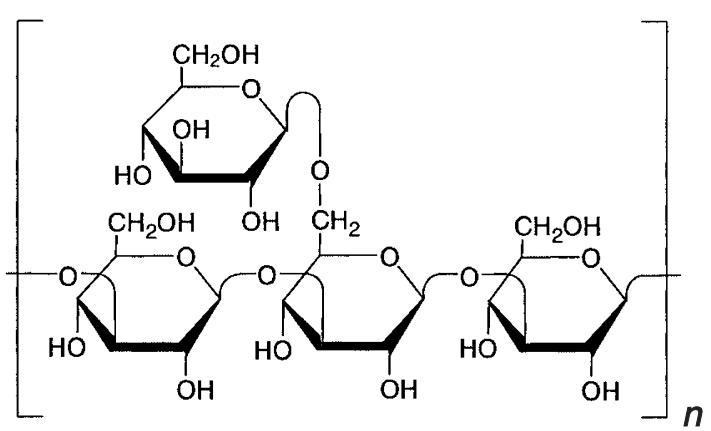

Figure 1. Chemical structure and repeating unit of schizophyllan.

is present in the renaturing process, a new triple helix consisting of one polynucleotide chain and two sSPG chains is formed instead of reforming the original triple helix. ${ }^{4}$ Mizu et al. ${ }^{9}$ demonstrated that poly(dA) forms a complex with s-SPG and the complex exhibits the following features. (1) A critical base number is necessary to induce the complexation. (2) When the base number is $>60$, the poly $(\mathrm{dA})$ chain in the complex undergoes structural transition upon heating below the dissociation temperature $\left(T_{\mathrm{m}}\right)$ of the complex. This is a distinct conformational transition and we denote the low and higher temperature forms as $\mathrm{HL}$ and $\mathrm{H}$, respectively. (3) The hypochromic effect once ceases at the transition temperature and appears again. Such complicated CD spectral changes have never been observed for single-stranded RNAs such as poly(C), poly(A), and 
(a)

$$
\mathrm{P}-\mathrm{P} \text { distance }=7 \AA
$$

( Glycosidic torsional angle: syn

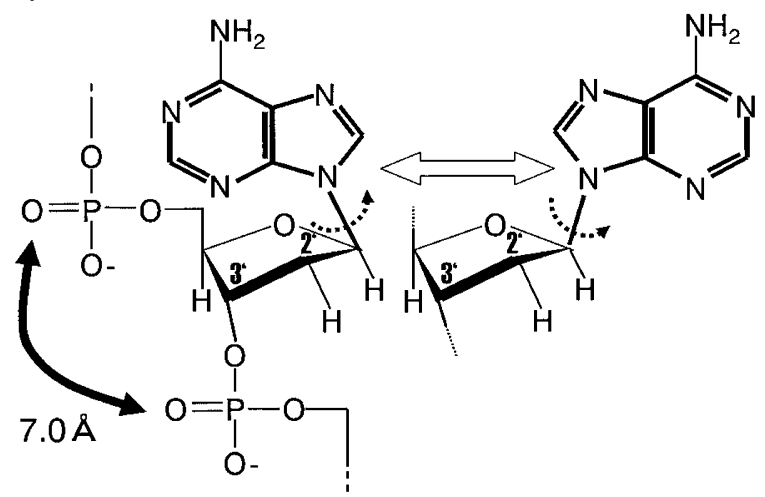

(b) C3'-endo

$\mathrm{P}-\mathrm{P}$ distance $=5.9 \AA$

( Glycosidic torsional angle: only anti)

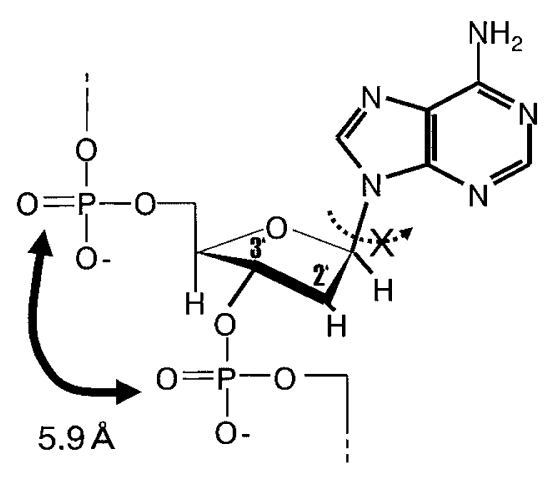

Figure 2. Schematic illustration of the conformational notation of polynucleotides. (a) $C 2^{\prime}$-endo puckering. For this puckering, the torsional angle of the glycosidic bond can be allowed to take two forms: anti and syn. The distance between the phosphate anions is $7.0 \AA$. (b) $C 3^{\prime}$-endo puckering. This puckering allows only anti form and the distance between the phosphate anions is $5.9 \AA$.

poly $(\mathrm{U}){ }^{4,10}$ This spectral diversity is characteristic of poly $(\mathrm{dA})$ and may be related to the conformational flexibility of DNA. ${ }^{11}$ This paper examines the solvent effect of the complex made from poly(dA) and s-SPG to clarify the nature of this unique structural transition.

\section{CONFORMATIONAL NOTATION OF POLYNUCLEOTIDES AND THE CD SPECTRUM FOR POLY(DA)}

According to conformational studies on polynucleotides, ${ }^{1,12}$ the ribose ring of ribonucleosides usually takes the $C 3^{\prime}$-endo puckering and the ribose in deoxyribonucleosides takes the $C 2^{\prime}$-endo puckering. Here, the $C 3^{\prime}$-endo puckering (or N-type) is a ribose puckering in which the $C 3^{\prime}$ carbon is out-of-plane projecting out toward the same direction of the base moiety, and the $C 2^{\prime}$-endo puckering (or S-type) is defined in the same manner (see Figure 2). Torsional freedom around the glycosidic bond greatly differs between $C 2^{\prime}$-endo and $C 3^{\prime}$-endo. The $C 3^{\prime}$-endo puckering only takes the anti conformation which causes the WatsonCrick hydrogen-bonding sites to be directed far away from the ribose ring. The $C 2^{\prime}$-endo puckering enables the base to rotate rather freely and to take both anti and syn conformations. The syn form is an almost reverse position of the anti form, with Watson-Crick hydrogen-bonding sites now oriented towards the ribose. Generally, the anti form is more preferable than the syn form, however, the stability difference depends on the base molecules and the atmosphere surrounding the molecules. When the base is adenine, anti is more preferable than syn. The energy difference between those (anti and syn) is only $0.3 \mathrm{kcal} \mathrm{mol}^{-1},{ }^{12}$ small enough to convert each other. The electrostatic interaction between the phosphate anions plays an important role to determine the polynucleotide conformation, especially, the salt concentration dependence of the conformation. The distance between the adjacent phosphate anions is about $5.9 \AA$ for the $C 3^{\prime}$-endo puckering, while $7.0 \AA$ for the $C 2^{\prime}$-endo puckering. ${ }^{1}$ Therefore, $C 2^{\prime}$-endo is more preferable in lower salt concentrations than $C 3^{\prime}$-endo, because electrostatic repulsion is less sealed in the lower salt concentration. The sugar puckering and the glycosidic bond angle are not defined as one conformation, but as a group of conformations having a similar steric parameter. ${ }^{12}$ Polynucleotide chains contain $C 2^{\prime}$-endo and $C 3^{\prime}$-endo at the same time.

Circular dichroism in the $240-300 \mathrm{~nm}$ wavelength range reflects the spatial relationship between the adjacent bases along polynucleotides through the interactions between the induced dipole moment of the bases. Olsthoorn et al. ${ }^{13,14}$ extensively studied the relationship between the CD spectra and the chain conformation of poly $(\mathrm{dA})$ determined by NMR, and found that the poly $(\mathrm{dA})$ chain consists of $C 2^{\prime}$-endo and anti $\left(S_{\mathrm{dA}}\right)$ as a major species and $C 3^{\prime}$-endo and anti $\left(N_{\mathrm{dA}}\right)$ as a minor one, and with increasing the chain length, the population of $N_{\mathrm{dA}}$ essentially vanishes. ${ }^{15}$ Since the population of $N_{\mathrm{dA}}-N_{\mathrm{dA}}$ should be negligible, only two combinations for the adjacent bases essentially determine the CD spectra, that is, $S_{\mathrm{dA}}-S_{\mathrm{dA}}$ and $S_{\mathrm{dA}}-N_{\mathrm{dA}}$ sequences. The CD spectra for $S_{\mathrm{dA}}-S_{\mathrm{dA}}$ and $S_{\mathrm{dA}}-N_{\mathrm{dA}}$ sequences are characterized to have a strong negative band at $250 \mathrm{~nm}$ and a weak positive band at $280 \mathrm{~nm}$, and a strong negative band at $250 \mathrm{~nm}$ and a strong positive band at $260 \mathrm{~nm}$, respectively. 
(a) Non-salt, neutral

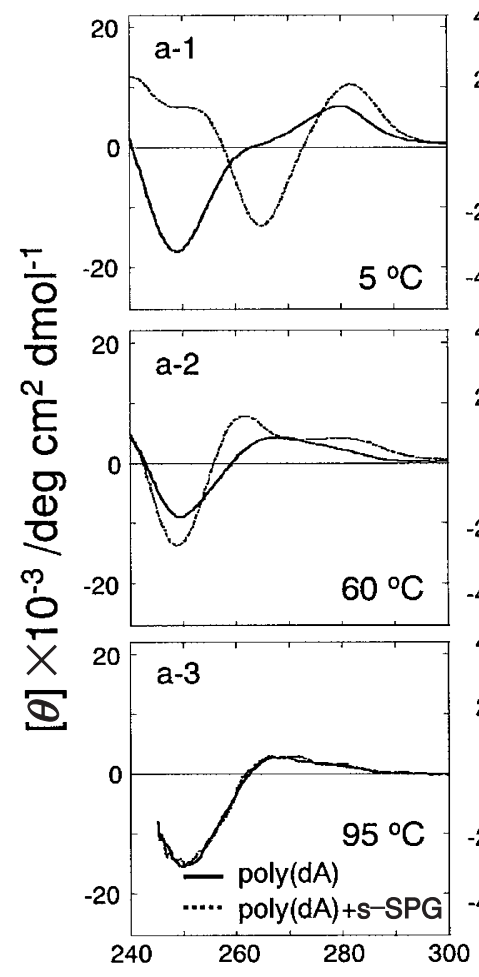

(b) $1 \mathrm{M} \mathrm{KCl}$
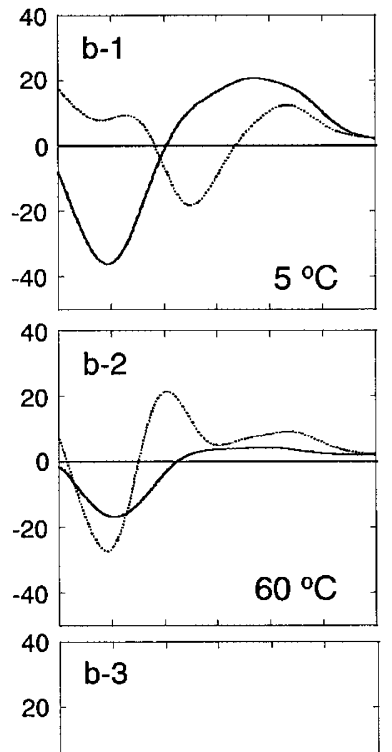

(c) $2 \mathrm{M} \mathrm{KCl}$
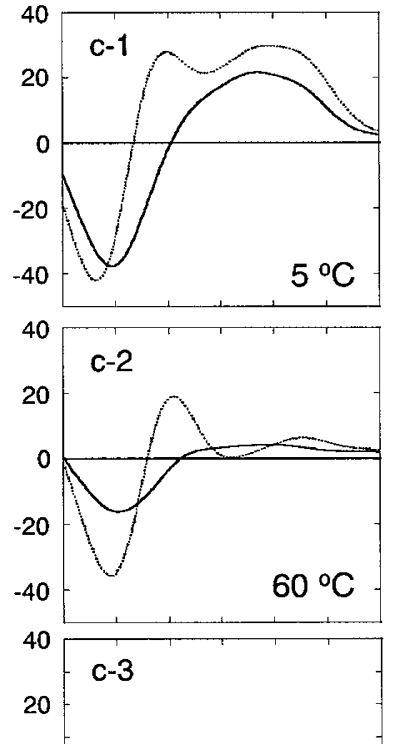

(d) Non-salt, neutarl
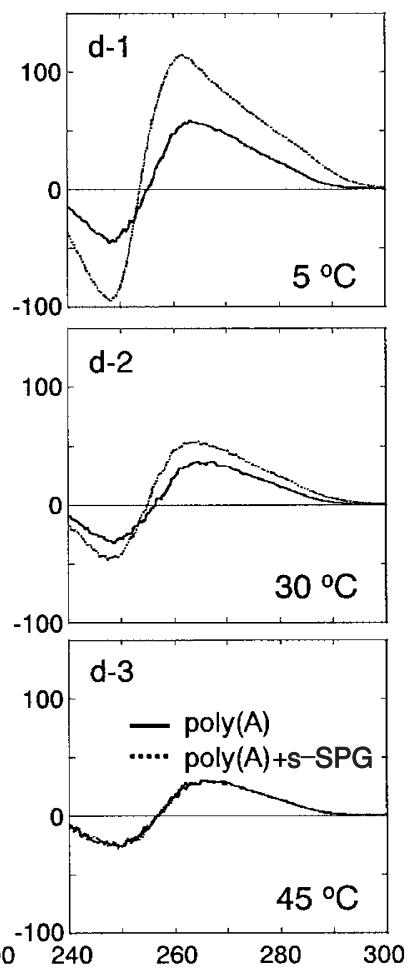

\section{Wavelength $/ \mathrm{nm}$}

Figure 3. Comparison of the $\mathrm{CD}$ spectra in three solutions containing poly(dA) (non-salt and neutral: (a), $1 \mathrm{M} \mathrm{KCl:} \mathrm{(b),} \mathrm{and} 2 \mathrm{M} \mathrm{KCl}$ (c)) at 5, 60, and $95^{\circ} \mathrm{C}$. For reference, poly(A) is shown in panel (d). In all panels, the solid and dotted lines represent the CD spectra for poly $(\mathrm{dA})$ and the mixtures of poly(dA) and s-SPG.

\section{EXPERIMENTAL}

High-purity grades of $\mathrm{NaCl}, \mathrm{KCl}, \mathrm{DMSO}, \mathrm{D}_{2} \mathrm{O}$, and formamide were purchased form Wako Chemical. Poly(dA) and poly(dT) were obtained from Amersham Phamacia and the degrees of polymerization, based on reported sedimentation velocities, were about 250 and 300 , respectively. According to the previous work, ${ }^{9}$ the poly (dA) base number of 250 was considered sufficient to ignore the chain end effect. The schizophyllan sample was kindly provided by Taito Co. in Japan. The molecular weight of s-SPG was $1.5 \times 10^{5}$, i.e., 231 repeating units. A mixture of poly(dA) and s-SPG was prepared by adding a DMSO solution of s-SPG to an aqueous solution of poly(dA). Final concentrations of poly(dA) and s-SPG were $5.3 \times 10^{-3} \mathrm{~g} \mathrm{dL}^{-1}$ and $5.0 \times 10^{-2} \mathrm{~g} \mathrm{dL}^{-1}$, respectively. The volume fraction of water in the mixture was 0.91 for all samples. Before measurements, all samples were annealed at $5{ }^{\circ} \mathrm{C}$ for $6-10 \mathrm{~d}$. The $\mathrm{CD}$ and ultraviolet absorbance (UV) spectra in the 240-300 $\mathrm{nm}$ region were measured at $0-95^{\circ} \mathrm{C}$ on a Jasco J-720WI spectropolarimeter and Jasco V-570 UV/VIS/NIR spectrophotometer, respectively. The CD and UV spectra depended only on the salt concentration, and the difference in cations did not provided any change. $T_{\mathrm{m}}$ was determined according to the established method. ${ }^{4,9,10}$

\section{RESULTS AND DISCUSSION}

\section{Conformational Transition on Heating in Non-Salt and Neutral Solutions}

Figure 3 presents the CD spectra in three solutions containing poly(dA) (non-salt and neutral: (a), $1 \mathrm{M}$ $\mathrm{KCl}$ : (b), and $2 \mathrm{M} \mathrm{KCl:} \mathrm{(c))} \mathrm{at} \mathrm{5,} \mathrm{60,} \mathrm{and} 95^{\circ} \mathrm{C}$. For comparison, the poly(A) system is presented in panel (d). In all panels, the solid and dotted lines represent the CD spectra for poly $(\mathrm{dA})$ and the mixtures of poly(dA) and s-SPG. Here, the mixture does not necessarily means the complex, but it may just consist of sSPG and polynucleotide, individually. Hereinafter, we denote the complex and mixture as poly $(\mathrm{dA}) / \mathrm{s}-\mathrm{SPG}$ and poly $(\mathrm{dA})+\mathrm{s}-\mathrm{SPG}$, respectively. s-SPG is CD inactive at this wavelength, so that all change in $\mathrm{CD}$ should be ascribed to conformational changes in poly(dA).

In panel (a-1), there is considerable spectral difference between poly(dA) and poly (dA)/s-SPG. The spectrum of poly(dA) exhibits a typical feature for $S_{\mathrm{dA}^{-}}$ $S_{\mathrm{dA}}$, showing a strong negative band at $250 \mathrm{~nm}$ and a 
weak positive band at $280 \mathrm{~nm}$. Poly(dA)/s-SPG demonstrates an exciton-couple type band, showing a strong positive band at $283 \mathrm{~nm}$ and a new negative band at $265 \mathrm{~nm}$. In the previous communication, ${ }^{9}$ this spectrum was denoted as HL (see appendix) and, as far as we know, we have never seen such a spectral shape for poly $(\mathrm{dA})$ and its derivatives. This is characteristic of the poly(dA)/s-SPG complex. On considering the origin of the CD spectrum in this range, the appearance of the new spectra suggests that the spatial relationship between the adjacent adenine moieties is drastically altered upon the complexation. The movement of the adenine in poly $(\mathrm{dA})$ is achievable because the puckering in poly $(\mathrm{dA})$ is $C 2^{\prime}$-endo. Thus the rotation around the glycosidic bond is allowed. Although determination of the exact torsional angel is impossible from $\mathrm{CD}$ data, the vanishing $250 \mathrm{~nm}$ negative band (characteristic of anti for both $C 2^{\prime}$-endo and $C 3^{\prime}$-endo) suggests that the syn form is one possibility for this novel CD pattern in the complex. We can thus conclude that the complexation induces the movement of the adenine from anti to a completely new form (maybe syn); as a consequence, the CD spectrum is drastically changed on the complexation. The spectral changes upon the complexation for poly $(\mathrm{dA})$ are quite contrast with poly(A) (d-1) in which the complexation does not change the spectral shape but it only enlarges the intensity. This contrast between poly $(\mathrm{A})$ and poly $(\mathrm{dA})$ can be ascribed to the difference in the ribose puckering between poly(A) and poly(dA); therefore, the puckering in poly(A) is $C 3^{\prime}$-endo so that only anti is allowed.

At $95{ }^{\circ} \mathrm{C}$ in the non-salt and neutral solution, the poly $(\mathrm{dA})$ in the complex undergoes conformational transition $\mathrm{HL}$ to $\mathrm{H}$ before the dissociation of the complex. Panel (a-2) presents the $\mathrm{CD}$ spectrum for $\mathrm{H}$ at $60^{\circ} \mathrm{C}$ (dotted line), clearly showing considerable difference from HL (dotted line in a-1). Comparing with the CD spectrum of $S_{\mathrm{dA}}-N_{\mathrm{dA}}$ reported by Olsthoorn et al. ${ }^{13} \mathrm{H}$ is identical to their spectrum, having a strong negative band at $250 \mathrm{~nm}$ and a strong positive band at $260 \mathrm{~nm}$. Therefore, $\mathrm{H}$ can be ascribed to a poly $(\mathrm{dA})$ conformation containing $C 3^{\prime}$-endo and anti as a minority among the majority of $C 2^{\prime}$-endo and anti.

\section{Salt Concentration Dependence of the Poly(dA) Con- formation}

When we increased $\mathrm{KCl}$ concentration at $5^{\circ} \mathrm{C}$ (compare (a-1), (b-1), and (c-1) in Figure 3), the poly (dA) spectrum (solid line) increases the intensity around $275 \mathrm{~nm}$ with maintaining the $250 \mathrm{~nm}$ negative band. This indicates that there is a new conformation in the higher salt solution. Hereinafter, we label it as SA. In comparison of the solid lines between (c-1) and (d-
1), the overall spectral shape of SA is quite similar to that of poly(A). In the previous work, ${ }^{1}$ poly(A) takes $C 3^{\prime}$-endo and anti, so that the similarity suggests that poly(dA) also takes $C 3^{\prime}$-endo and anti in the $2 \mathrm{M}$ and $1 \mathrm{M} \mathrm{KCl}$ solution. This is a reasonable conclusion from the standpoint that the salts reduce the electrostatic repulsion between the phosphate anions. The distance between the adjacent phosphate anions is about $5.9 \AA$ in $C 3^{\prime}$-endo, while it is $7.0 \AA$ in $C 2^{\prime}$-endo. Therefore, in the non-salt solution, $C 2^{\prime}$-endo is more preferable than $C 3^{\prime}$-endo and this seems the main reason why poly(dA) takes $C 2^{\prime}$-endo in the non-salt solution. When a suitable amount of salts is added, the electrostatic repulsion becomes less important and other factors determine the conformation.

When we examine the salt-concentration dependence of the spectrum for poly $(\mathrm{dA})$ at $5^{\circ} \mathrm{C}$ [solid lines in (a1), (b-1), and (c-1) in Figure 3], the spectrum changes from $S_{\mathrm{dA}}$ to SA between 0 and $1 \mathrm{M} \mathrm{KCl}$. The complex maintains $\mathrm{HL}$ at $1 \mathrm{M} \mathrm{KCl}$ and the spectral change occurs between 1 and $2 \mathrm{M}$. In $2 \mathrm{M} \mathrm{KCl}$, the spectrum of the complex seems to consist of $\mathrm{H}$ and SA. This indicates that the poly $(\mathrm{dA})$ chain in the complex takes almost $C 3^{\prime}$-endo and anti in $2 \mathrm{M} \mathrm{KCl}$. When we increased temperature in $2 \mathrm{M} \mathrm{KCl}, \mathrm{H}$ was maintained and the $275 \mathrm{~nm}$ positive band disappeared, indicating that at $2 \mathrm{M} \mathrm{KCl}$, the $\mathrm{H}$ conformation dominates at all temperatures. Therefore, there is no conformational transition on heating in the $2 \mathrm{M} \mathrm{KCl}$ solution.

Figure 4 summarizes the salt concentration dependence of the CD spectrum of poly(dA)/s-SPG, compared with that of poly $(\mathrm{dA})$. At the low temperature and low salt concentration, the poly $(\mathrm{dA})$ in the complex takes the HL form, which is estimated to be $C 2^{\prime}$-endo with the different torsional angle from the anti form. With increasing temperature, $\mathrm{HL}$ changes to $\mathrm{H}$, which bears characteristics of $C 3^{\prime}$-endo and anti as a minority among the majority of $C 2^{\prime}$-endo and anti (i.e., $\mathrm{S}_{\mathrm{dA}^{-}}$ $\left.N_{\mathrm{dA}}\right)$. When the salt concentration is increased, the spectrum changes to combination of $\mathrm{SA}$ and $\mathrm{H}$, with disappearing $\mathrm{HL}$ at $5^{\circ} \mathrm{C}$ and $\mathrm{H}$ form is dominated at $60^{\circ} \mathrm{C}$.

\section{Melting Behavior of the Complex and Comparison with Poly (dA)/Poly(dT) Duplex}

Figure 5 compares the temperature dependence of UV absorbance at $257 \mathrm{~nm}$ for poly $(\mathrm{dA})$, poly $(\mathrm{dA})+\mathrm{s}-$ SPG in non-salt and neutral, and poly $(\mathrm{dA})+\mathrm{s}-\mathrm{SPG}$ in $2 \mathrm{M} \mathrm{NaCl}$. For poly(dA), the absorbance increases with increasing temperature, due to the decrease in the helix content in the original $C 2^{\prime}$-endo and anti form. ${ }^{1,12,13,16}$ For poly $(\mathrm{dA})+\mathrm{s}$-SPG in non-salt and neutral, the absorbance at $0{ }^{\circ} \mathrm{C}$ is lower than that of poly $(\mathrm{dA})$ because 
$\operatorname{poly}(d A)$

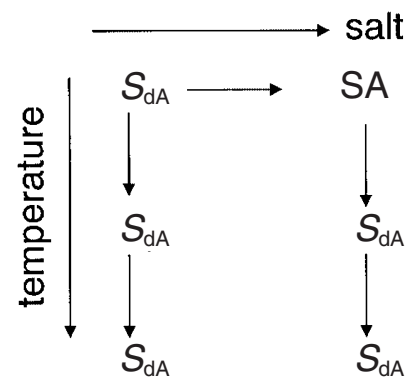

poly $(d A) / s-S P G$

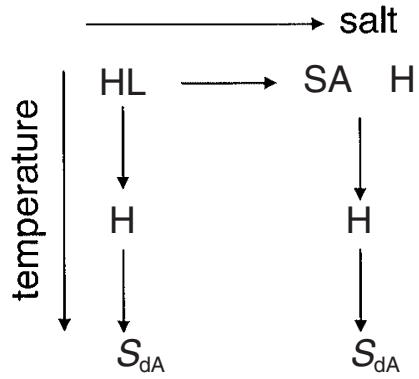

$S_{\mathrm{dA}}:$ C2'-endo and anti for poly $(\mathrm{dA})$ chain

$N_{\mathrm{dA}}$ : C3'-endo and anti for poly(dA) chain

$\mathrm{HL}$ : high molecular weight and low temperature form, C2'-endo in that the torsion of the glycosidic bond is different from $S_{\mathrm{dA}}$, it can be syn

$\mathrm{H}$ : high temperature form, $C 3^{\prime}$-endo and anti as a minority among the majority of $C 2$ '-endo and anti

$\mathrm{SA}$ : conformation of poly $(\mathrm{dA})$ itself in higher salt concentrations

Figure 4. Summary of the salt concentration dependence of the CD spectrum of poly(dA)/s-SPG, compared with that of poly(dA).

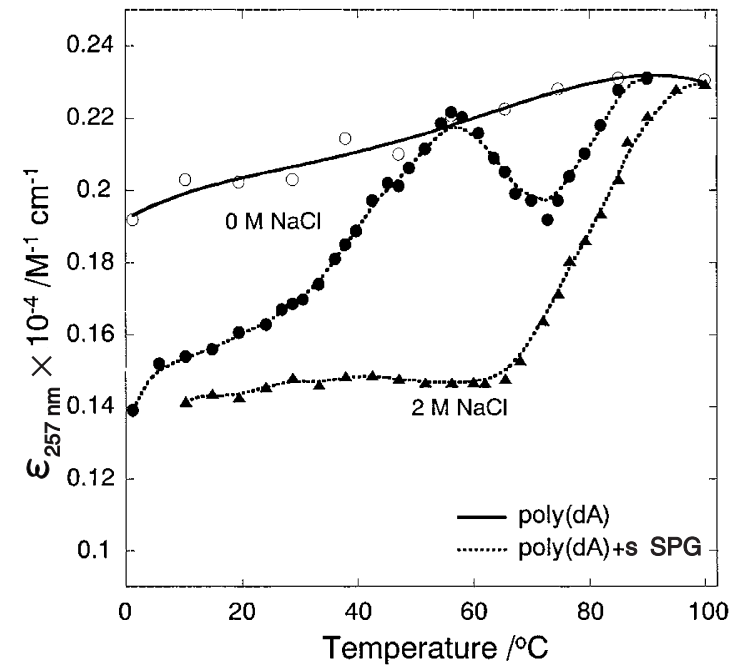

Figure 5. Temperature dependence of UV absorbance at $257 \mathrm{~nm}$ for poly $(\mathrm{dA})$, poly $(\mathrm{dA})+\mathrm{s}-\mathrm{SPG}$ in the non-salt and neutral solution, and poly $(\mathrm{dA})+\mathrm{s}-\mathrm{SPG}$ in $2 \mathrm{M} \mathrm{NaCl}$.

of the hypochromic effect due to the complexation. On heating, it stays at a lower value than that of poly $(\mathrm{dA})$ at $T=0-50{ }^{\circ} \mathrm{C}$, then increases to the same value with poly(dA), and again shows the lower absorbance than that of poly(dA) in $T=60-95^{\circ} \mathrm{C}$ before the dissociation of the complex. The disappearance of the hypochromic effect is consistent with the conformational transition before melting. In sharp contrast to the non-salt and neutral solution, the complex in $2 \mathrm{M} \mathrm{NaCl}$ dose not show such disappearance. There is thus no conformational transition.

Figure 6 plots $T_{\mathrm{m}}$ against $\mathrm{NaCl}$ concentration comparing between poly(dA)/s-SPG and poly $(\mathrm{dA}) /$ poly(dT). When $\mathrm{NaCl}$ concentration is less than $5 \mathrm{mM}$, there is no hybridization for the poly $(\mathrm{dA})+\operatorname{poly}(\mathrm{dT})$

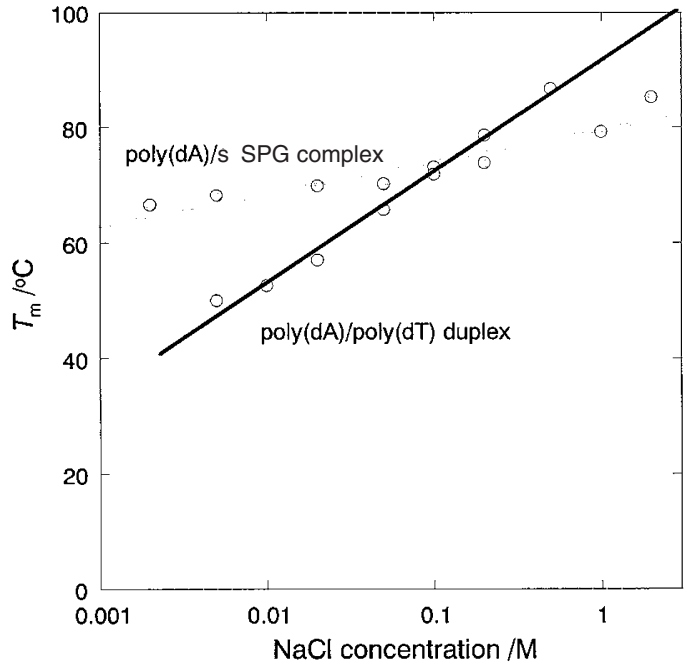

Figure 6. Comparison of $\mathrm{NaCl}$ concentration dependence of $T_{\mathrm{m}}$ for poly(dA)/poly(dT) duplex and poly(dA)/s-SPG complex.

mixtures, Because both poly $(\mathrm{dA})$ and poly(dT) are polyanions, so that the electrostatic repulsion between the cations has to be shielded by salts in order to form the duplex. ${ }^{1,17,18}$ With increasing $\mathrm{NaCl}$ concentration $([\mathrm{NaCl}]), T_{\mathrm{m}}$ increases $100^{\circ} \mathrm{C}$ at $[\mathrm{NaCl}]=2 \mathrm{M} . T_{\mathrm{m}}$ of the complex is insensitive to $[\mathrm{NaCl}]$, compared to the poly(dA)/poly(dT) duplex. For the complex, $T_{\mathrm{m}}$ increases from 65 to $75^{\circ} \mathrm{C}$ when $[\mathrm{NaCl}]$ increases from 0 to $2 \mathrm{M}$. This may be the schizophyllan chain having no electrical-charge so that there is no electrostatic repulsion between s-SPG and poly(dA). The small increment in $T_{\mathrm{m}}$ in the complex is contrast to that of PNA/DNA complex, in that $T_{\mathrm{m}}$ decreases slightly with increasing $[\mathrm{NaCl}] .{ }^{19,20}$ PNA is a peptide nucleic acid in which the phosphodiester backbone has been replaced by a pseudo-peptide chain, so that there is no electronic 
(e) $10 \% \mathrm{CHONH}_{2} / \mathrm{DMSO}$

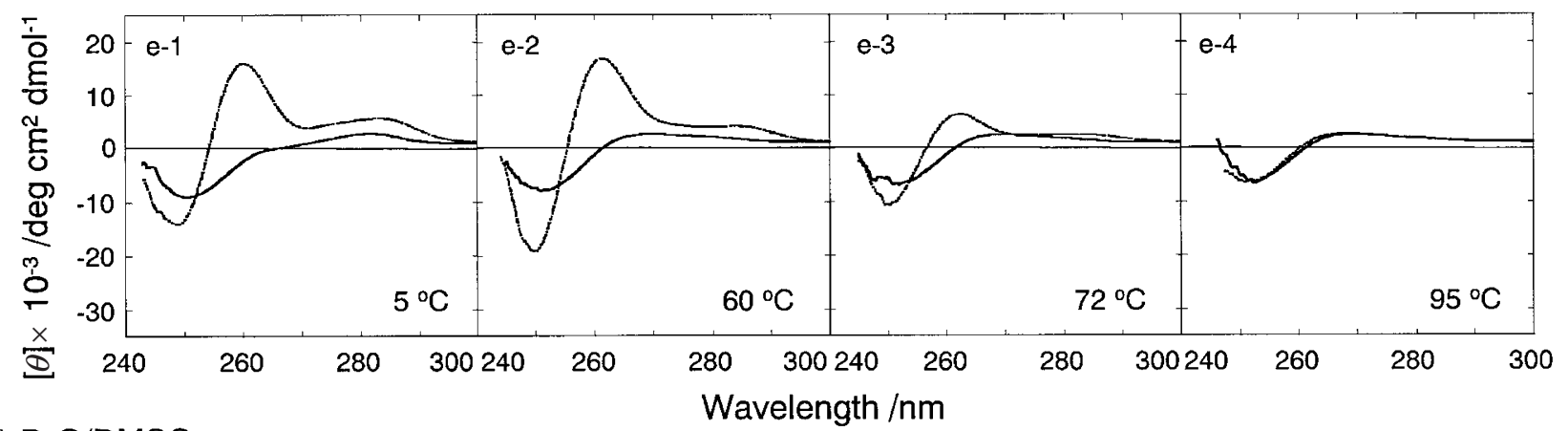

(f) $\mathrm{D}_{2} \mathrm{O} / \mathrm{DMSO}$

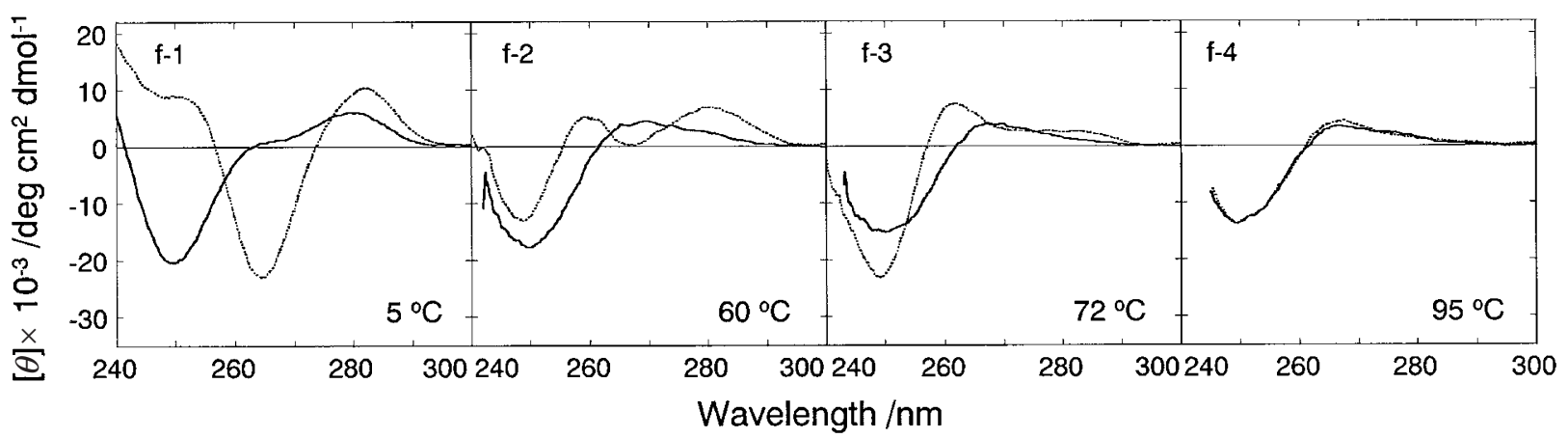

Figure 7. Temperature dependence of the CD spectra for poly $(\mathrm{dA})$ and poly $(\mathrm{dA})+\mathrm{s}-\mathrm{SPG}$ in (e) $10 \%$ formamide and (f) $\mathrm{D}_{2} \mathrm{O}$ solution.

change in the chain. ${ }^{21}$ The reason for increase $T_{\mathrm{m}}$ with increasing $[\mathrm{NaCl}]$ is not clear, but possibly related to the conformational change in poly(dA).

\section{Addition of $\mathrm{D}_{2} \mathrm{O}$ or Formamide}

Figure 7 shows the temperature dependence of the CD spectra for poly (dA) and poly (dA) + s-SPG in aqueous solution containing $10 \mathrm{vol} \%$ formamide/DMSO and in $\mathrm{D}_{2} \mathrm{O} / \mathrm{DMSO}$. Formamide cleaves the hydrogen bonding. Poly $(\mathrm{dA})$ decreases the $\mathrm{CD}$ intensity at $250 \mathrm{~nm}$, suggesting decrease in the helix content. As shown in (e-1), the CD spectrum of the complex in the formamide solution at $5{ }^{\circ} \mathrm{C}$ is quite similar to that of the non-salt and neutral solution at $60^{\circ} \mathrm{C}$. On comparing (e-1) and (a-2), formamide induces the same effect as increasing temperature. The addition of formamide enlarges the $\mathrm{H}$ conformation range.

When we exchanged the solvent for $\mathrm{D}_{2} \mathrm{O}$ (Figure 7 (f-1)), the $\mathrm{CD}$ spectrum at $5{ }^{\circ} \mathrm{C}$ is essentially the same as that of the $\mathrm{H}_{2} \mathrm{O}$ system. However, the $\mathrm{HL}$ form is not replaced by the $\mathrm{H}$ form at $60^{\circ} \mathrm{C}$ (see (f-2)) and the transition temperature form $\mathrm{HL}$ to $\mathrm{H}$ can be evaluated to be $72{ }^{\circ} \mathrm{C}$, which is $12^{\circ} \mathrm{C}$ higher than that of the $\mathrm{H}_{2} \mathrm{O}$ system. Therefore, $\mathrm{D}_{2} \mathrm{O}$ induces the same effect as decreasing temperature.

\section{SUMMARY}

The relationship between the conformation and sol- vent for the poly(dA)/s-SPG complex was examined. The diverse and complicated CD spectra for the poly $(\mathrm{dA}) / \mathrm{s}-\mathrm{SPG}$ complex can be explained by the conformational diversity of the ribose puckering and the freedom of the torsional angle of the glycosidic bond for the adenine. This new sight should broaden our horizon to understand the novel interaction between polysaccharides and polynucleotides.

\section{APPENDIX}

Figure 8 shows the $\mathrm{CD}$ spectral change on heating for the poly $(\mathrm{dA}) / \mathrm{s}-\mathrm{SPG}$ complex. The spectra at $0^{\circ} \mathrm{C}$ are different from those reported in the previous paper. The previous HL spectrum had a small negative band at $250 \mathrm{~nm}$, whereas, the present one, a positive shoulder around $250 \mathrm{~nm}$. The low temperature spectrum for poly(dA)/s-SPG (i.e., HL) was subsequently found to depend on annealing conditions. The longer annealing time provides the smaller negative band at $250 \mathrm{~nm}$ and one week is sufficient for saturation. In this work, all samples were left at $5^{\circ} \mathrm{C}$ for at least one week and longer than one week did not provide an appreciable change in the CD spectrum. As shown in the figure, the spectra obtained in the temperature range of $0-60{ }^{\circ} \mathrm{C}$ (upper panel) have isosbestic points at 257 and $280 \mathrm{~nm}$, and those at $65-90^{\circ} \mathrm{C}$ (lower panel) have isosbestic points at 254 and $270 \mathrm{~nm}$. The upper panel is totally different from the lower panel. These isosbestic 


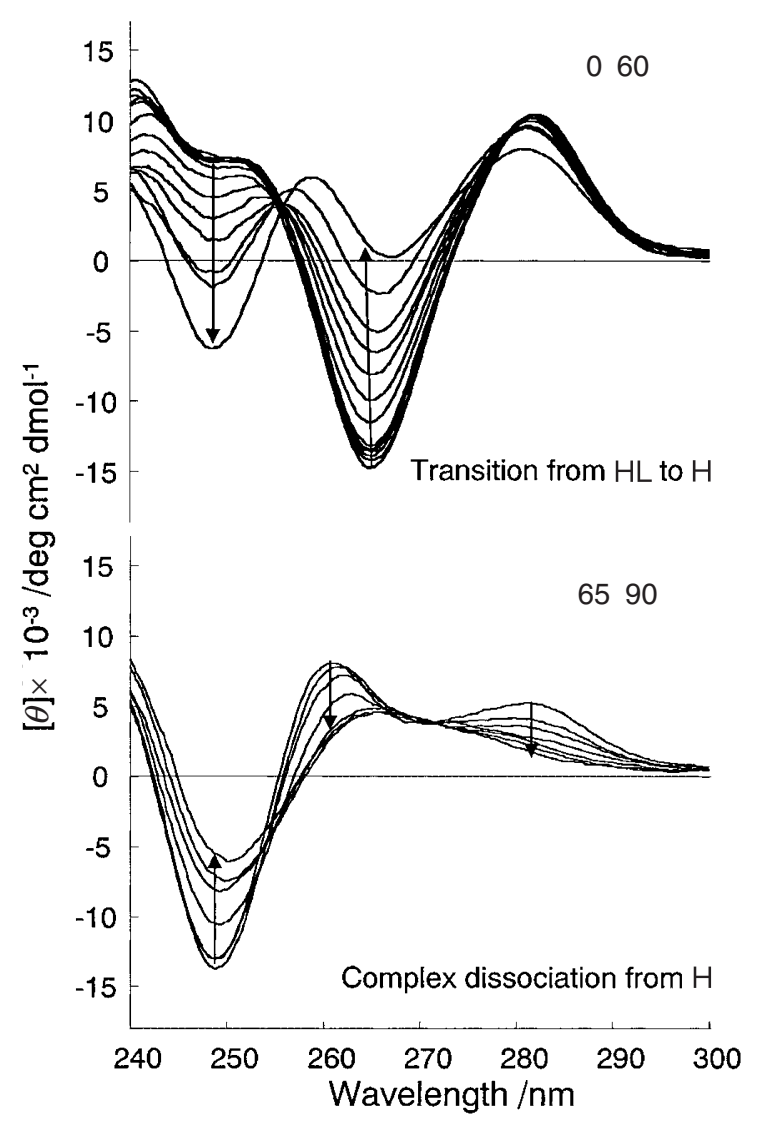

Figure 8. Temperature dependence of the CD spectra for poly $(\mathrm{dA})+\mathrm{s}-\mathrm{SPG}$ in non-salt and neutral solution. Upper panel shows the changes between $0-60{ }^{\circ} \mathrm{C}$ and the lower panel, $65-90^{\circ} \mathrm{C}$.

points indicate that the $\mathrm{CD}$ spectrum involves two competing conformations in equilibrium and one conformation becomes dominant on heating. Figure 8 thus confirms the poly $(\mathrm{dA})$ chain in the complex undergoes a conformational transition on heating below $T_{\mathrm{m}}$ of the complex, and the low and high temperature forms are designated as $\mathrm{HL}$ and $\mathrm{H}$, respectively.

Acknowledgment. This work is finically supported by the "Organization and Function", PRESTO, and SORST programs in Japan Science and Technology Corporation (JST).

\section{REFERENCES AND NOTES}

1. W. Saenger, in "Principles of Nucleic Acid Structure", Springer-Verlag, New York, N.Y., 1984.

2. J. W. Chase and K. R. Williams, Ann. Rev. Biochem., 55, 103 (1986).

3. M. D. Powell and D. M. Gray, Biochemistry, 34, 5635 (1995).

4. K. Sakurai and S. Shinkai, J. Am. Chem. Soc., 122, 4520 (2000).

5. K. Tabata, W. Ito, T. Kojima, S. Kawabata, and A. Misaki, Carbohydr. Res., 89, 121 (1981).

6. T. Norisuye, K. Yanaki, and H. Fujita, J. Polym. Sci., 18, 547 (1980).

7. K. Yanaki, T. Norisuye, and H. Fujita, Macromolecules, 13, 1462 (1980).

8. T. M. McIntire and D. A. Brant, J. Am. Chem. Soc., 120, 6909 (1998).

9. M. Mizu, T. Kimura, K. Koumoto, K. Sakurai, and S. Shinkai, Chem. Commun., 429 (2001).

10. K. Sakurai, M. Mizu, and S. Shinkai, Biomacromolecules, 2 , 641 (2001).

11. N. Berova, K. Nakanishi, and R. W. Woody, Eds., "Circular Dichroism: Principles and Application”, 2nd ed, Wiley-VCH, Canada, 2000.

12. N. Stephen, in "Nucleic Acid Structure and Recognition", Oxford University Press Inc., London, 2002.

13. C. S. M. Olsthoorn, L. J. Bostelaar, J. F. M. Rooij, J. H. van Boom, and C. Altona, Eur. J. Biochem., 115, 309 (1981).

14. C. S. M. Olsthoorn, L. J. Bostelaar, J. H. van Boom, and C. Altona, Eur. J. Biochem., 112, 95 (1980).

15. $S_{\mathrm{dA}}$ and $N_{\mathrm{dA}}$ specifically stand for the $C 2^{\prime}$-endo and anti and $C 3^{\prime}$-endo and anti conformations for poly(dA) chain.

16. V. V. Filimonov and P. L. Privalov, J. Mol. Biol., 122, 645 (1978).

17. B. Pullman and A. Pullman, Progr. Nucl. Acid Res. Mol. Biol., 9, 327 (1969).

18. D. Porschke, Mol. Biol. Biochem. Biophys., 24, 191 (1977).

19. M. Egholm, O. Buchardt, L. Christensen, C. Behrens, S. M. Freier, D. A. Driver, R. H. Berg, S. K. Kim, B. Norden, and P. E. Nielsen, Nature, 365, 566 (1993).

20. S. Tomac, M. Sarkar, T. Ratilainen, P. Wittung, P. E. Nielsen, B. Norden, and A. Graslund, J. Am. Chem. Soc., 118, 5544 (1996).

21. P. E. Nielsen and G. Haaima, Chem. Soc. Rev., 26, 73 (1997). 